\title{
Experience Analysis on Forest Healing - Based on the Record of Experience of Forest Healing -
}

\author{
Ok Hee Park', Jae Yong Lee ${ }^{2}$, and Myung Hee Hong ${ }^{1}$ \\ ${ }^{1}$ Department of Forest Therapy, Chungbuk National University, Cheongju 28644, South Korea \\ ${ }^{2}$ Department of Education, Chungbuk National University, Cheongju 28644, South Korea
}

\begin{abstract}
The purpose of this study was to investigate the motivation, healing purpose, healing process and healing effect of forest through experiential essays. These essays of 34 forest experience were collected from 2014 to 2015 at Forestry Administration Office. Five steps of analysis were used including self-observation, self-description, selfdiscovery, equality and differentiation, and verification. The results of the study are as follows. First, there were psychological instability factors such as depression, bipolar disorder, helplessness, social phobia, and social maladjustment, and these factors were related to physical illness or family history of patients. Second, the process of self-discovering by self-observation and self-description in forest experience was expressed, and this experience is interpreted to strongly support the effects of various forest healing proved empirically in previous studies. Third, the patients experienced similar sufferings such as depression, anxiety, and frustration, but they described as experiencing the process optimized for each unique characteristic in the motivation, necessity, accessibility, and program utilization of each experience. Ultimately, the participants felt positive change in senses and emotions such as refreshing, comfort, relaxation, and euphoria through the natural vitality of forests that is inhaled through the five senses. They learnt to reflect on themselves and shame, and they could rediscover the value and meaning of life while meaningfully recognizing the problems attributed to them.
\end{abstract}

Keywords: equality and differentiation, self-description, self-discovery, self-observation, verification

\section{Introduction}

Forest healing can be understood as forest activities in which various natural environmental factors of a forest such as landscape, sound, scent, phytoncide, anion, water, light, climate, and topography commune physically, sensuously, and mentally with human body tissues to promote mental and physical health (Lee, 2012). Academically, forest healing can be defined as physical and mental healing utilizing various health and medical healing factors of a forest (Kim, 2006). In light of this definition, healing through forests is closely linked to our lives, so it is a meaningful attempt to focus on the specific process of forest healing.

According to earlier studies on forest healing, healing effect of a forest was found in single mothers (Song et al., 2009), elderly people (Lim et al., 2014), women (Kim et al., 2013a; Lee and Shin, 2015), nurses (Song et al., 2014), teachers (Cho et al., 2015), adolescents (Kim et al., 2013b; Jung et al., 2014; Oh et al., 2016a), and children (No et al., 2014),

Received: July 26, 2017, Revised: August 3, 2017, Accepted: August 7, 2017

*Comesponding author: jesuslights@naver.com 
without any restriction on specific situation, age, sex, and occupation. There were psychological instability factors found in the study such as depression, stress, and anxiety. Forest experience had positive effects on healing chronic schizophrenic patients (Lee et al., 2011) and children (elementary school students) with atopic dermatitis (Lee et al., 2016; Seo et al., 2012), alcoholics (Song, 2005; Cho et al., 2008), and prenatal care (Lee and Song, 2015). This is because the various factors of a forest such as landscape, green vision, sound (Kim, 2007) and phytoncide (Ham et al., 2011; Kang, 2000) have positive effects on people's physiological, sensory, and mental and physical health.

In this context, this study aims to provide an in-depth analysis on what motivates people to visit forest, healing process and healing results based on the self-confessions described in the forest healing experiential essays, and present a meaningful implication as to why forest is used as an effective alternative for people's well-being and well-aging. Experiential essay presupposes literary credibility of a self-confessing record that vividly and truthfully conveys writer's experiences, thoughts, emotions and feelings through forest experience. Therefore, it is considered that, in this experiential record, writer's contemplation and insight based on his/her situation, self-reflection and healing process are expressed through the literary genre of essay (Oh et al., 2016b). Especially, this study intends to strongly support the results validated empirically in the previous studies by suggesting the effectiveness of forest healing demonstrated through actual experiences, rather than applying numerical survey results or inferential statistical analysis techniques.

\section{Study Method}

The purpose of this study is to investigate the motivation, healing purpose, healing process and healing effect of forest in essays of 34 forest experience, collected from 2014 to 2015 at the Forest Recreation Management Division of the Korea Forest Service (KFS). The experiential essays referred to in this study are selected by the Korea Green Promotion Agency and the Korea Forest Welfare Institute with transparent and reliable criteria in terms of competition purpose, applicant qualification, examination standards and awards. The experiential essays, the main subject of this study, presupposes literary credibility of a self-confessing record that vividly and truthfully conveys writer's experiences, thoughts, emotions and feelings through forest experience. Therefore, it is considered that, in this experiential record, writer's contemplation and insight based on his/her situation, self-reflection and healing process are expressed through the literary genre of essay (Oh et al., 2016b).

The experience analysis is a qualitative research method developed by Price and Barrell (1980), in which a person experiencing a series of phenomena directly enters his or her own experience and grasps the identity of the experience phenomenon, helping find a strategy to effectively respond to the experience (Park, 2004). This study analyzes the essays recording the forest healing experiences, actively and voluntarily experienced by the participants. The purpose of this is to identify the effects of forest healing by collecting and analyzing the emotions, feelings, and psychological processes that can not be directly observed, presupposing their authenticity and reliability. Five steps of analysis were used including self-observation, self-description, self-discovery, equality and differentiation of experience and verification, based on the major cases in the experiential essays (Lee and Lee, 2015; Yun, 2009). In each of the 34 individual experiential essays, the process of these five steps is described explicitly or figuratively, but the results were interpreted focusing on cases positively highlighting the subject of this study. In addition, if required in each step, generalization and robustness of the process and meaning of the forest healing experience was derived by citing the results that have been academically verified in the previous studies and matching them with the cases in each essay. 


\section{Results and Consideration}

\section{Study Data}

Table 1 shows the analysis on the demographical distribution of the winners in the 2014 and 2015 competition- winning forest experiential essays.

As for gender, there were 13 men and 21 women, and the proportion of women was higher at $61.8 \%$. The participants were 22 individuals, followed by family ( 8 persons) and group ( 4 persons). The subjects of the demographic analysis of this study are not the writers of the experiential essays but those who actually experienced forest healing. For example, even if the essay was written by a mother, if the participant was a teenager son, then the participant was classified as a man, a teenager (10's), with the corresponding reason for healing.

The average age of the participants was 1 person in 10's (2.9\%), 6 in 20's (17.6\%), 4 in 30's (11.8\%), 1 in 40's (2.9\%), 2 in 50's (11.8\%), 2 in 60's (5.9\%), and 16 unknown (47.1\%). The age of the sixteen unknown was guessable, but they were not included in the statistics as the guess was inaccurate.

The most common pathologic feature of the participants was 15 cases of depression, which were described as complex symptoms combined with external factors such as disease and family history, except for one case of simple depression. Among them, 8 cases were patients suffering diseases (stomach, peritonitis, uterine myoma, multiple infarcts, visual disturbance of child, and mother's heart disease). In addition, there were many other cases found such as aftereffect of retirement, Tourette's disorder, social maladjustment, unfortunate family history, and student's depression. There were seven cases of ill patients and post-treatment (pneumonia, ankylosing spondylitis, thymus cancer, breast cancer, and gastric cancer), five cases of mental treatment (genetic predisposition to family disruption, anxiety / irritability due to husband's death and illness, husband's self-injury of wrist, side effects from pregnancy, aftereffect from traffic accident),

Table 1. Demographical distribution of winner in the forest experience handball competition.

\begin{tabular}{|c|c|c|c|c|c|}
\hline Category & Division & 2014 & 2015 & Total & Ratio (\%) \\
\hline \multirow{3}{*}{ Gender } & Man & 7 & 6 & 13 & 38.2 \\
\hline & Woman & 10 & 11 & 21 & 61.8 \\
\hline & Sub total & 17 & 17 & 34 & 100.0 \\
\hline \multirow{4}{*}{ Participation form } & Individual & 8 & 14 & 22 & 64.7 \\
\hline & Family & 6 & 2 & 8 & 23.5 \\
\hline & Group & 3 & 1 & 4 & 11.8 \\
\hline & Sub total & 17 & 17 & 34 & 100.0 \\
\hline \multirow{8}{*}{ Age } & 10 's & 0 & 1 & 1 & 2.9 \\
\hline & 20 's & 2 & 4 & 6 & 17.6 \\
\hline & 30 's & 0 & 4 & 4 & 11.8 \\
\hline & 40 's & 1 & 0 & 1 & 2.9 \\
\hline & 50 's & 2 & 2 & 4 & 11.8 \\
\hline & 60 's & 1 & 1 & 2 & 5.9 \\
\hline & Unknown & 11 & 5 & 16 & 47.1 \\
\hline & Sub total & 17 & 17 & 34 & 100.0 \\
\hline
\end{tabular}


stress (psychological anxiety due to parental divorce, lethargy due to family troubles), communication with students, addiction (game, internet), two cases of atopy and one case of ADHD.

10 cases were found where participants were engaged in forest activities in mountains and parks not far from their residence, which was highest in number, followed by nearby mountains, forest trekking, recreation forests, arboretums, and residence relocation. Participants visited mountains near residences mainly to relieve physical and mental distress and get treatment, and stated that they visited nearby hills and parks. After experiencing forest at a nearby location and feeling the positive effects, they expanded the scope of experience to a remoter area or actively participated in other various programs.

\section{Self-observation}

In the self-observation step of experiential essays, free but true feelings were recorded without any prejudice or prejudgment at the moment of experience (Lee, 2016). First of all, the cases and effects of self-observation through the hands-on forest experiences are as follows.

"As I walked through the forest and had time to take a walk with my mom and hang out with my friends on a regular basis, I became less aggressive and more caring and thoughtful." (Case 'Walking with the Black Dog')

"If I just leave it like this, apparently it would be a repetition of my past life again. I could not resist the temptation of the day I was dreaming a sweet dream and visited Jeolmul Natural Forest Resort." (Case 'I am thankful for the forest.')

"In the morning, she walked from Yonghyun Natural Forest to Gorransa Temple, and in the afternoon she walked to Bowansa Temple, humming a song." (Case "Another child for forest mother")

"I was alone in the woods but was not lonely. I became a walking tree in the woods, so I became comfortable and happy to be assimilated into nature. I learned simple thought, humble thought. It seems that recovery of health has been given as a bonus." (Case, 'Mountain, the Land of Healing')

"I wonder if all these things are the happiness that the mountain has brought. I am busy with the idea that I can climb mountains after a little while. The wind is cool and I feel refreshed.” (Case, 'The gift given by the mountain')

Philippa (2012) emphasizes that, at the stage of psychotherapy, self-observation can be a starting point for change through relationships with others, helpful stress, and personal statements. Participants first looked into their inner world in the forest. Through the forest, the participants expressed various aspects of their mental state and mental movements. These self-observation was expressed to motivate participants to look back on their unfortunate past and to visit forest more actively and repeatedly.

\section{Self-description}

The second is the self-description step. The self-description step is to state the specific experiences such as imagery, thought, sense, behavior, and emotion found at the self-observation step from the first person's present view (Lee, 2016). This study examined whether the experiences of major changes were described, such as the trigger and situation of healing in the forests, the emotions and sentiments during the healing process, and the specific process of forest healing.

Although the experiential essay states forest experience with a present tense, it vividly describes the past experiences such as the healing process, method and effect. The step of self-description shown in the experiential essay frankly expresses the psychological instability including the pain and depression from diseases, and conveys physical and psychological healing and stability through forest experience. 
"I regretted having married at a young age, and I got divorced, and after divorce, I got social phobia and bipolar disorder. I thought that if I had a divorce, I would be able to go back to my original status, but there was a bigger pain waiting and the way to forget this pain was to rely on alcohol. Continuing this, I got a disease called uterine myoma." (Case, 'Road Invited to Happiness')

"At a young age of 37, a small, old cough made me see a doctor and I was diagnosed with thymus cancer. At this critical juncture, I was forced to go to the hill at the back of my house, and there, greed, resentment, and hatred disappeared. I realized that healing of mind comes before healing of body." (Case, 'Drug named Forest')

"I got thyroid cancer just before my child entered elementary school. I also got depression due to my husband's blunt reactions, and when I was preparing for my child's schooling, my stress became worse.” (Case, 'The second drug given by my child')

"I had to move to another place three times because of my troublemaker eldest child, and as I saw no signs of improvement, I took him to a complete medical check up, and he was diagnosed with Attention Deficit Hyperactivity Disorder (ADHD).” (Case 'A gift given by mountain')

"Marriage at a young age", "divorce", "uterine myoma", "thymus cancer", and "ADHD" described above are the records of facts experienced by the participants, and a process of describing oneself from an honest and contemplative view. Assuming that the essay is similar to a diary describing a series of events over time, it would not be easy to reveal own privacy to strangers. Nevertheless, paradoxically, the self-description in the above essays removes the participants' defense mechanism, making them calmly state their past based on facts. In addition, unstable psychological states such as 'social phobia and bipolar disorder', 'regret', 'dependence on alcohol', 'psychological pain', and 'healing of mind before healing of body' are honestly described. Finally, the essays introduce the process of overcoming such as 'walking in the hill at the back of my house', 'discovering new ideas', 'cool oxygen on the forest road' and 'the best prescription medicine'. By asking questions about their past and giving answers through this self-description process, the participants convey the effects of forest healing to readers.

\section{Self-discovery}

The third step is self-discovery. In this step, the forest healing experiences written in individual essays were repeatedly read to compare, compile, and analyzes similar experience processes. First, the factors that raised the need for forest healing (common factors) were identified. These common factors can directly appear in the described sentences, or be implied in intrinsic and implicit words. At this step, we examined how each factor is expressed in the forest experience. In order to prevent the distortion of the contents of experience, cautions were taken not to include preconceptions, prejudgment, and the interpretation of researchers. Table 2 summarizes the experience-inducing factors (common factors) which appear in the essays. The common factors of self-discovery after the forest experience include a deep reflection on oneself and their relationship with others, and the experience of realizing many things that they did not know before.

As shown in Table 3, in the experiential essays, common factors were found in terms of the timing of forest healing, triggers and the factors changing emotions and feelings. These essays show that the difficult past can lead to natural change and growth, as the feeling of comfort and well-being doubles through forest experience. In addition to the two cases, the forest healing process throughout the course of the essay shows a new way of building relationship with oneself, people around them and the nature. 
Table 2. Common factors of forest healing self-discovery.

\begin{tabular}{|c|c|}
\hline Category & Content \\
\hline $\begin{array}{l}\text { Triggering } \\
\text { factor }\end{array}$ & $\begin{array}{l}\text { Disease: cerebral infarction, cancer pruritus cutaneous, atopic dermatitis, hypertension, sequela, pneumonia, } \\
\text { peritonitis, uterine myoma, visual disturbance, Pregnancy side effects, ankylosing spondylitis, tourette's disorder, } \\
\text { ADHD } \\
\text { Family related: unfortunate marriage and divorce, spouse self-harm, gambling and game addiction, after effective } \\
\text { retirement, death of a family member } \\
\text { Etc: forest healing experience, meeting with the disciples }\end{array}$ \\
\hline Symptom & $\begin{array}{l}\text { Depressive disorder, bipolar disorder, irritation, lethargy, suicide attempt, stress, insomnia, migraine, social } \\
\text { maladjustment, emptiness, social phobia }\end{array}$ \\
\hline $\begin{array}{l}\text { Self-discovery after } \\
\text { forest experience }\end{array}$ & $\begin{array}{l}\text { A vain desire, obsession, stubborn, I know the arrogance, complaint, I looked back on myself when I was irritated, } \\
\text { as the forest realizes the sacrifice without pay, the emotions become aware, a real appreciation, familiarity with } \\
\text { family }\end{array}$ \\
\hline
\end{tabular}

Table 3. Example of self-discovery in experience handwriting.

\begin{tabular}{|c|c|c|}
\hline \multirow{2}{*}{ Category } & \multicolumn{2}{|c|}{ Self-discovery } \\
\hline & Case 1 & Case 2 \\
\hline Triggering factor & $\begin{array}{l}\text { Mother's cerebral infarction, beggars and swearing to } \\
\text { caregivers, depression deepening of mother }\end{array}$ & $\begin{array}{l}\text { School violence resulting from the humiliation of the } \\
\text { weak, anger and revenge as a result of sexual degradation }\end{array}$ \\
\hline Symptom & $\begin{array}{l}\text { Severity of malicious language and abuse to the } \\
\text { caregiver become stronger. }\end{array}$ & Insomnia, obsession, complex, defeat \\
\hline Self-discovery & $\begin{array}{l}\text { My mother's depression is due to her children, my } \\
\text { mother is trying to make up for what she has done to } \\
\text { others, knowing the sacrifice of the forest. }\end{array}$ & Looking back on my anxious past. \\
\hline
\end{tabular}

Table 4. Equality and differentiation in cases of depression.

\begin{tabular}{|c|c|c|c|}
\hline \multirow{2}{*}{\multicolumn{2}{|c|}{ Equivalence of experience }} & \multicolumn{2}{|c|}{ Differentiation of experience } \\
\hline & & Case 1 & Case 2 \\
\hline \multirow{3}{*}{ Depression } & Cause & $\begin{array}{l}\text { It just hurt somewhere. } \\
\text { Helplessness, stomachache. } \\
\text { Mother died. }\end{array}$ & $\begin{array}{l}\text { Relative deprivation. } \\
\text { Father's business failure. } \\
\text { Poverty and money. }\end{array}$ \\
\hline & Lapse & $\begin{array}{l}\text { Weight loss after marriage. } \\
\text { Suicide attempt. } \\
\text { Difficulty in childbirth and childcare. }\end{array}$ & $\begin{array}{l}\text { Undergraduate university entrance. } \\
\text { Alcohol and game addiction. }\end{array}$ \\
\hline & Cure & $\begin{array}{l}\text { Invitation to co-parentage of forest. } \\
\text { Bipolar disorder after daily return. } \\
\text { Joint child care re-entry. } \\
\text { Effects of Forest Healing Program. } \\
\text { Acquired certificate of forest healing company. }\end{array}$ & $\begin{array}{l}\text { Mountain climbing to the top. } \\
\text { Sweat, quiet breathing, concentration. } \\
\text { Compliance. } \\
\text { I found myself neglected. } \\
\text { Desired forest specialization. }\end{array}$ \\
\hline
\end{tabular}

\section{Equality and Differentiation of Experience}

The fourth step is equality and differentiation of experience. It appeared that most of the participants have experienced daily pain due to depression, anxiety and frustration, although they had slight differences in pre-experience emotions and feelings. However, they state that their negative stress has been eliminated or mitigated through forest experience.

Table 4 summarizes the unique healing process of depression (including bipolar disorder, lethargy, etc.), most frequently 
seen in the experiential essays. The process of individual healing (differentiation of experiences) of similar pain called depression (equality of experience) can manifest differently.

According to what the participants individually describe in the experiential essays, they have similar experience effects, although the words or expressions used are different. This can be regarded as equality reflecting the fundamental characteristics of forest experiences. However, the participants are described as experiencing the process optimized for their own characteristics in terms of motivation, necessity, accessibility, and program utilization of each experience. This can be regarded as differentiation of experiences.

\section{Verification}

The final step in this study is verification. The researchers verified the study results after getting consensus from a group of experts (forest healing professor, forest healing professionals, etc.) Based on this verification results, they went through the process of revising and supplementing the experiences, common factors and psychological processes of forest healing (Lee, 2016).

As a result of the verification, it was agreed that forests have a very positive effect on the interaction of human emotion, cognition, and behavior. The process of forest healing identified in the verification step is shown in Fig. 1. The participants experienced forest healing due to physical factors (such as atopy treatment), psychological factors (disagreement with family), and external factors (such as recommendation of acquaintance). The experience of forest healing can be divided into external recognition and internal reaction. The external recognition of forest healing includes visual experience (such as looking out to the forest), auditory experience (wind in the forest, listening to grass sounds), olfactory experience (such

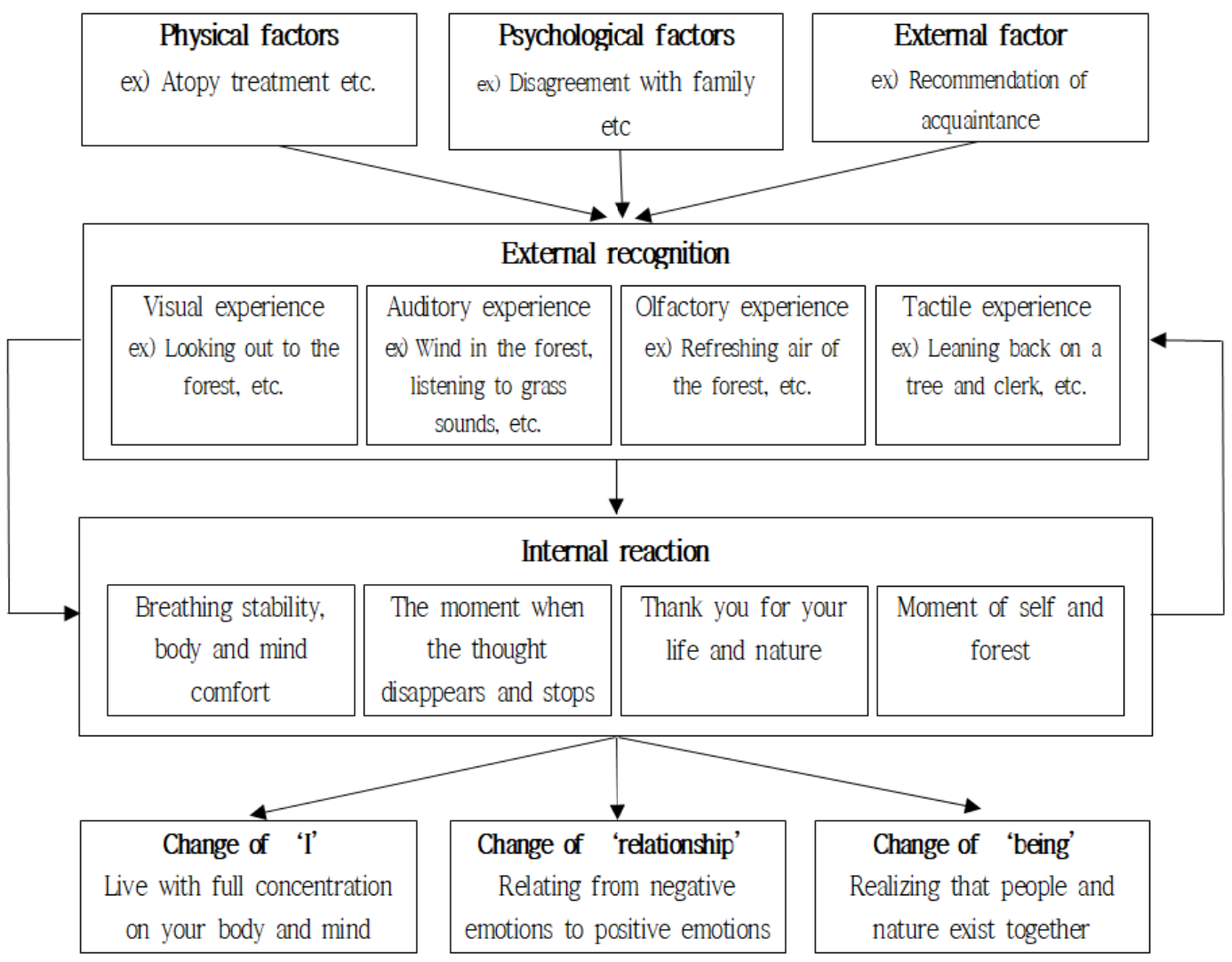

Figure 1. Psychological process of forest healing experience. 
as refreshing air of the forest), tactile experience (such as leaning back on a tree or touching). The external recognition of forest healing was linked to internal reaction, such as breathing stability, body and mind comfort, the moment when the though disappears and stops, gratitude for life and nature, and moment of self and forest External recognition and internal reaction of forest healing were repeated cyclically, and in this process, the participants experienced change.

The changes caused by forest healing experience were seen in three areas: 'I', 'relationship', and 'being'. In the 'I' area, it changed to living with full concentration on one's body and mind. In the 'relationship' area, it changed to relating from negative emotions to positive emotions. In the 'being' area, it changed to realizing that people and nature exist together. The participants experienced cyclic and repetitive changes in me, relationships, and beings through the experience of forest healing.

Starting with feeling positive emotions from the forest, the participants began to experience forest through selfobservation and self-description. The participants have been recorded as feeling positive change in senses and emotions through the natural vitality that is inhaled through the five senses by the influence of the healthy factors of forests already identified and proven in previous studies. This is the image of the self that the participants find themselves, and the mood at this time is expressed as refreshing, comfort, relaxation and euphoria.

This self-discovery is the process of experiencing the essential self, the reflective self, and the realistic self (Shin, 2009). The participants describe that they learn to reflect on themselves and learn shame, while meaningfully recognizing the problems attributed to them and rediscover the value and meaning of life through forest experience. In addition, they recover their health and soundness and improve self efficacy, adapting well to everyday life with positive spirit of challenge.

These results are almost consistent with the various effects of forest experiences proven by scientific methods in previous studies. The cases in the experiential essays show that the nature and its sound revive dull senses and barren feelings, and provide the opportunities for self-reflection and self-observation, which was not experienced in cities, such as the healing effect of forests that reduces aggressiveness (Kim et al., 2015a; Kim et al., 2015b), disappearance of the anger that resents the world (Kim et al., 2013b; Kim et al., 2015c), sympathy with parents(Lim, 2008; Shin et al., 2013), and experience of euphoria, refresh and comfort (Kim et al., 2013a; Lee and Song, 2015). Ultimately, the various and infinite factors provided by forests will refresh five senses and promote emotional and sentimental stability, alleviating diseases and suffering in life and turning negative pessimism into active and positive attitudes towards life (Shin, 2009).

\section{Conclusion}

This study qualitatively analyzed the process of positive change of emotions, feelings, mentality and attitudes, by looking into the essays written by those who had forest experience. It was found that the physical diseases, psychological instability, maladjustment in family and surroundings, and abnormal addictive symptoms were the factors that raised the need for forest healing. Depression, bipolar disorder, frustration, lethargy, suicide attempts, stress, insomnia, migraine, social maladjustment, emptiness, and social phobia were the main symptoms. Forest experience provided an opportunity to look into the inner world littered with vain desire, obsession, stubbornness, and arrogance, and to take time to discover self who was always irritated and annoyed. As a result, participants realize the unconditional sacrifice of the forest and naturally grow appreciation for the infinite offerings from the forest.

This study is differentiated from previous studies in that it qualitatively analyzed the meaning of forest healing by taking the self-confessions made in the essays that won the 'Forest Healing Experience Essay Competition' held between 2014 and 2015 and going through the steps of self-observation, self-description, self-discovery, equality and differentiation 
of experiences and verification. However, there is a limit to the analysis in that it was only based on the essays of the people who experienced forest healing. In the future, it would be necessary to try and collect various data through not only essay competition but also various other practical processes such as interviews, observations, and discussions. In addition, it would be also necessary to analyze forest healing experiences by specific factors such as age, group, occupation, and place of experience. It is our expectation that more follow-up studies will be conducted to generalize the effects of forest healing using various interdisciplinary research methodologies, which will establish more specific and individual forest healing programs.

\section{References}

Cho, H.S., S.M. Cho, and J.G. Cha. 2008. Therapeutic effects of the forest-healing program on alcohol dependance patients and their families. Korean J. Health Psychol. 13(3):727-743.

Cho, M.N., C.S. Shin, P.S. Yeon, and J.Y. Kim. 2015, April. The effects of the forest healing program according to job-stress, fatigue, mood state of the elementary school teachers. Paper presented at the 2015 Union Conference on Forest Science, Jeju, Korea. Abstract retrieved from http://www.dbpia.co.kr/Journal/ArticleDetail/NODE06299035

Ham, G.J., K.Y. Park, M.S. Kim, J.M. Song, S.S. Lee, and Y.S. Ok. 2011. Research of monoterpenes content in the atmosphere of forest. Korean J. Soil Sci. Fertil. 44(6):1226-1231.

Jung, D.W., D.G. Yeom, C.W. Kwon, G.W. Kim, J.H. Choi, and B.J. Park. 2014, November. Study on lasting effect of forest healing of youth through the accommodation type forest program. Paper presented at the Fall Conference on Korean Institute of Forest Recreation and Welfare. Abstract retrieved from http://www.dbpia.co.kr/Journal/ArticleDetail/ NODE06240830

Kang, H.Y. 2000. The secret of phytoncide. Historynet, Seoul, Korea.

Kim, B.S., H.Y. Kim, and S.J. Lee. 2013a. The effect of forest experiences on happiness and positive psychology of korean middle-aged women in seoul and the surrounding metropolitan cities. J. Korean Inst. For. Recreat. 17(3):65-73.

Kim, I.O., P.S. Yeon, W.S. Shin, and I.J. Kim. 2013b. The influence of a forest experience program on elementary school student's anger. J. Korean Inst. For. Recreat. 17(2):55-61.

Kim, J.Y., C.S. Shin, P.S. Yeon, J.Y. Lee, M.R. Kim, J.G. Kim, and Y.H. Yu. 2013. Forest healing program impact on the mental health recovery of elementary school students. J. Korean Inst. For. Recreat. 17(4):69-81.

Kim, K.W. 2006. Theoretical study of characteristics of therapeutic elements and application to forest therapy. J. People Plants \& Environ. 9(4):111-123.

Kim, K.W. 2007. Forest aesthetics. Kookmin Univ., Publishing, Seoul, Korea.

Kim, S.A., D.O. Chung, G.O. Kim, and B.G. Park. 2015a. The effect of forest activities on attitude toward forest and mental health of elementary school students. J. Korean Inst. For. Recreat. 19(4):35-43.

Kim, S.A., D.W. Jung, D.G. Yeon, G.W. Kim, and B.J. Park. 2015b. The effects of forest activities on attitudes toward forest, stress, self-esteem and mental health of children in community child centers. J. Korean Inst. For. Recreat. 19(3):51-58.

Kim, Y.G., S.H. Lee, Y.H. Kim, J.O. Eom, Y.R. Lim, T.G. Ha, and C.S. Shin. 2015c. The influence of forest activity intervention on anxiety, depression, profile of mood states (POMS) and hope of cancer patients. J. Korean Inst. For. Recreat. 19(1):65-74.

Lee, G.M., G.W. Kim, and Y.C. Jung. 2011. Study on monitoring of forest healing program on schizophrenia. Paper presented at the Spring Conference on Korean Institute of Forest Recreation and Welfare. Abstract retrieved from http://www.dbpia.co.kr/Journal/ArticleDetail/NODE01866058

Lee, I.S., G.S. Bang, S.J. Kim, H.S. Choi, B.H. Lee, and M.G. Song. 2016. Effect of forest program on atopic dermatitis in children, a systematic review. J. Korean Inst. For. Recreat. 20(2):1-13. 
Lee, J.Y. 2016. A phenomenological study on elementary school teacher's self-reflection experience. PhD Diss., Chungbuk Natl., Univ., Chungju, Korea.

Lee, J.Y. and J.Y. Lee. 2015. An experiential analysis of self-reflection in elementary school teachers. Koran J. Teach. Educ. 31(2):219-241. DOI: 10.14333/KJTE.2015.31.2.219

Lee, M.N. and J.S. Song. 2015. The effects of prenatal education in forest on the mindfulness and psychological well-being of pregnant woman. J. Korean Inst. For. Recreat. 19(4):25-34.

Lee, Y.H. 2012. A study on the forest management methods for therapeutic forest. PhD. Diss., Kookmin Univ., Seoul. Korea.

Lee, Y.J. and C.S. Shin. 2015. Effects of forest walking meditation on mood states and self-awareness in middle-aged women. J. Korean Inst. For. Recreat. 19(3):19-25.

Lim, Y.J. 2008. Children and parents' satisfaction and effect variation of summer family camp in korea national arboretum. J. Korean Inst. For. Recreat. 12(3):45-56.

Lim, Y.S., D.J. Kim, and P.S. Yeon. 2014. Changes in depression degree and self-esteem of senior citizens in a nursing home according to forest therapy program. J. Korean Inst. For. Recreat. 18(1):1-11.

No, H.J., C.S. Shin, P.S. Yeon, and S.H, Park. 2014. The impact of the activities in the forest on the number of the influenza drug administration to infants. J. Korean Inst. For. Recreat. 18(2):11-16.

Oh, G.H., D.J. Kim, J.G. Kim, and Y.S. Kim. 2016a. The effects of forest-healing program on developing youth activity competence. Korean J. Youth Stud. 23(2):1-24. DOI: 10.21509/KJYS.2016.02.23.2.1

Oh, G.H., D.J. Kim, and P.S. Yeon. 2016b. A psychological phenomena analysis of people who have experienced healing in the forest. Korean J. Environ. Ecol. 30(2):277-286. DOI: 10.13047/KJEE.2016.30.2.277

Park, S.H. 2004. Counseling research methodology. Hakjisa, Seoul, Korea.

Philippa, P. 2012. How to stay sane (The school of life). Picador, New York, USA.

Price, D. and J. Barrell. 1980. An experience approach with quantitative methods-A research paradigm. J. Hum. Psychol. 20(3):75-95.

Seo, S.C., S.H. Dong, I.S. Kang, K.N. Yeon, J.T. Chung, Y. Yoo, and C.W. Park. 2012. The clinical effects of forest camp on children with atopic dermatitis. J. Korean Inst. For. Recreat. 16(3):21-31.

Shin, O.S., M.H. Han, G. Park, and J.Y. Jang. 2013. The effect of family participated healing camps with the application of family life habit improvement on atopic dermatitis. J. Korean Inst. For. Recreat. 17(3):75-83.

Shin, Y.H. 2009. The poetic formulation of self-recognition appeared in self-portrait. Korean Lang. Lit. 68:277-308.

Song, J.H., J.G. Cha, C.Y. Lee, Y.S. Choi, and P.S. Yeon. 2014. Effects of forest healing program on stress response and spirituality in female nursing college students and there experience. J. Korean Inst. For. Recreat. 18(1):109-125.

Song, J.H., W.S. Shin, P.S. Yeon, and M.D. Choi. 2009. The influence of forest therapeutic program on unmarried mothers' depression and self-esteem. J. Korean For. Soc. 98(1):82-87.

Song, M.K. 2005. The effectiveness of anger control program of alcohol dependence. Korean J. Couns. Psychother. 17(2):367-381.

Yun, E.J. 2009. An experiential analysis of burnout in counselors. Korea J. Couns. 10(4):1855-1871. 